\title{
NON-ISOTHERMAL CREEP BEHAVIOR OF A SECOND GENERATION NI-BASED SINGLE CRYSTAL SUPERALLOY: EXPERIMENTAL CHARACTERIZATION AND MODELING
}

\author{
Jonathan CORMIER ${ }^{1}$, Xavier MILHET ${ }^{1}$, François VOGEL $^{2}$, José MENDEZ $^{1}$ \\ ${ }^{1}$ Laboratoire de Mécanique et de Physique des Matériaux ; Ecole Nationale Supérieure de Mécanique et d'Aérotechnique \\ 1 Avenue Clément Ader ; 86960 Futuroscope Chasseneuil ; France \\ ${ }^{2}$ Turboméca - SAFRAN group; 64511 Bordes; France
}

Keywords: Very high temperature creep, Burner rig, Dislocations, $\gamma^{\prime}$ dissolution/precipitation, Creep modeling

\begin{abstract}
In order to simulate emergency regimes possibly encountered by turboshaft engines for helicopter, non-isothermal creep behavior of the second generation single crystal Ni-Based superalloy MC2 was investigated. These tests were performed with one short overheating at $1200^{\circ} \mathrm{C}$ during the isothermal creep life of the material at $1050^{\circ} \mathrm{C}$. Overheatings were carried out using a burner rig designed to achieve temperature jumps as fast as $60^{\circ} \mathrm{C} / \mathrm{s}$ in the range $1050^{\circ} \mathrm{C}-1200^{\circ} \mathrm{C}$. Both the overheating duration and its position during the isothermal creep life at $1050^{\circ} \mathrm{C}$ of the material have a great effect on the non-isothermal creep behavior. The modifications in creep behavior were clearly linked with microstructural evolutions occurring during temperature changes, e.g: the dissolution of the $\gamma$ ' phase on heating the material and the dislocation recovery processes.
\end{abstract}

Based on these microstructure characterizations, a classical macroscopic model involving isotropic variables and a von Mises criterion was enhanced with the addition of new internal variables representative of the $\gamma^{\prime}$-volume fraction and a recovery function attesting for the dislocation activity.

\section{Introduction}

Single crystal nickel-based superalloys are widely used for the hottest part of jet engines such as high pressure turbine blades, where creep resistance is one of the operating life limiting factors. During a flight, turbine blades should not deform a lot as blade failure, or more likely blades touching the external housing generally leads to their damage in the engine. It is generally accepted that the entire turbine blade should not be permanently strained over $1 \%$ during operating life [1]. This critical deformation takes into account a wide range of thermal/mechanical loadings ranging from very high temperature/low stress in blade tips to low temperature/high stress in blade roots. Actually, Ni-based single crystal superalloys exhibit superior creep resistance at temperature as high as $1100^{\circ} \mathrm{C}$ [2] due to their particular microstructure, consisting of $70 \%$ in volume of coherently precipitated $\gamma^{\prime}$ cubes $\left(\mathrm{L}_{2}\right.$ lattice) separated by thin channels of face centered cubic (fcc) $\gamma$ matrix [3]. Extensive literature is devoted to the study of their properties, especially on isothermal creep over a wide range of stress and temperature [4-11]. Two temperature/stress domains can be distinguished: (1) at low temperature $\left(\mathrm{T}<950^{\circ} \mathrm{C}\right)$ and high stress, no significant evolution of the initial optimal microstructure occurs during the creep experiment, while (2) at higher temperature/lower stress, great modifications of the microstructure are observed during primary creep stage: rafting of the $\gamma^{\prime}$ phase perpendicular to the applied stress for negative $\gamma / \gamma^{\prime}$ misfit alloys and development of stable dislocation networks at the $\gamma / \gamma^{\prime}$ interfaces.

However, these studies cannot describe entirely the mechanical behavior of the material during a real flight since both stress and temperature are likely to vary depending on the engine rating. For example, emergency conditions such as a One Engine Inoperative (OEI) event can be encountered and are very different from the regular cruising regime. When an OEI event occurs on a twinengine helicopter, the remaining engine must provide enough power to maintain the helicopter airborne. In this case, the high pressure turbine blades of the remaining engine experience a sharp temperature jump from $1050^{\circ} \mathrm{C}$ to $1200^{\circ} \mathrm{C}$ during the time needed to recover almost regular cruising conditions. This produces non-isothermal creep conditions with the load only slightly increasing as the engine speed increases slightly, while the temperature varies due to the OEI simulation. In this context, long exposures of superalloys to extreme temperature are well documented in the literature [5, 13-17]: it provokes the dissolution of the $\gamma^{\prime}$ reinforcing phase and induces a severe loss in mechanical properties. In contrast, little is known about the mechanical behavior when the material is exposed to very high temperature transients, particularly when under load. For an engine designer, modeling the mechanical behavior of the superalloy during nonisothermal creep is essential to guarantee the engine integrity and to adopt best maintenance procedures. Yet, these materials were not designed originally to sustain such severe conditions. In particular, creep behavior and creep life after the OEI is of great interest. However, being able to reproduce realistic operating conditions in well-controlled laboratory conditions for various thermal and mechanical histories is a challenging issue, whether in terms of experimental characteristics (heating rate control and temperature levels), material characterization and mechanical modeling. The purpose of this paper is to address these issues by detailing: (1) a test bench specifically developed to simulate an OEI, (2) the non-isothermal creep behavior in relation to microstructure evolutions and finally, (3) a mechanical model based on a classical macroscopic approach, modified to attest for the microstructure evolutions. This study is particularly devoted to the second generation Ni-base superalloy $\mathrm{MC} 2$, currently in operation in various engines.

\section{Experimental techniques}

\section{Creep tests and simulation of the OEI}

The simulation of realistic flight conditions in a laboratory is a challenging issue, especially when complex thermal/load conditions are involved in components such as blades. However, it is a critical issue to understand fundamental aspects of the 
mechanical behavior of superalloys in their real environment. In fact, the experimental set-up has to reproduce as accurately as possible the harshest conditions encountered by turbine blades, i.e. very high temperature (up to $1200^{\circ} \mathrm{C}$ ), oxidizing environment and creep tensile stress around $140 \mathrm{MPa}$. Moreover, to meet the OEI specifications, the experimental set-up needs to be able to jump within seconds from $1050^{\circ} \mathrm{C}$, corresponding to regular cruising conditions, to $1200^{\circ} \mathrm{C}$, corresponding to emergency rating. Therefore, an OEI can be simply simulated by a specific non-isothermal creep test procedure: a jump in temperature from $1050^{\circ} \mathrm{C}$ to $1200^{\circ} \mathrm{C}$ has to be performed in the course of an isothermal creep test at $1050^{\circ} \mathrm{C} / 140 \mathrm{MPa}$. In this context, both pre-OEI and post-OEI creep conditions are pure isothermal creep at $1050^{\circ} \mathrm{C} / 140 \mathrm{MPa}$ and the OEI simulation $\left(1200^{\circ} \mathrm{C} / 140 \mathrm{MPa}+\right.$ $\Delta \sigma$ ) happens after a certain amount of pre-creep. However, if the the test seems fairly practical, it turns out to be a challenging issue due to the temperature levels and heating/cooling rates. Generally, creep tests are performed using either radiant or resistance furnaces. Unfortunately, in the OEI context, these two types of furnaces have very limited performances when dealing with temperature as high as $1200^{\circ} \mathrm{C}$, especially due to their slow temperature jump ability between $1050^{\circ} \mathrm{C}$ and $1200^{\circ} \mathrm{C}$. While it is not problem at $1050^{\circ} \mathrm{C}$ where the volume fraction of $\gamma^{\prime}$ phase is close to $60 \%$ at thermodynamic equilibrium, a slow temperature jump toward higher temperature leads to massive $\gamma^{\prime}$ dissolution [12], leading to a substantial modification of the behavior of the material. The heating rate of resistance furnaces in the temperature range considered in this study is only few degrees per minute, which makes it totally useless for studying the effect of an OEI on the material behavior. Radiant furnaces seem to be a little more capable to be used for the simulation of an OEI since they can achieve heating rates as high as $10^{\circ} \mathrm{C} / \mathrm{s}$. However, cooling rates over $1{ }^{\circ} \mathrm{C} / \mathrm{s}$ are difficult to obtain with this type of furnace at the temperature levels considered in this study. During the time needed to cool down the material to $1050^{\circ} \mathrm{C}$, massive dissolution of the $\gamma^{\prime}$ reinforcing phase takes place first, followed by a delayed reprecipitation of cubic nanometric precipitates in the $\gamma$ channels [13]. In this context, failure is observed within minutes after the overheating has occurred [14].

Based on these limitations, a specific test rig (STR) was designed to meet the requirements of the OEI simulations. It is a modified version of a test rig used to study the cooling of combustion chamber using multiperforated plates, equipped with a device applying a static tensile stress on the material during the entire non-isothermal creep experiment. Both very high temperature and very fast heating rates are achieved using a hot gas flow obtained by burning highly pressurized kerosene in a combustion chamber. The temperature of the hot gas flow, monitored using a thermocouple, is directly controlled by the pressure of the kerosene inlet. Using this configuration, heating and cooling rates as high as $60^{\circ} \mathrm{C} / \mathrm{s}$ can be expected. The specimen, heated up by forced convection, is loaded in a testing zone located at a sufficient distance from the flames to ensure homogeneous temperature of the gas flow and to prevent any contact with the flames. The temperature of the specimen is monitored using pyrometric measurements. In order to limit the specimen drag due to the gas flow velocity $\left(\approx 100 \mathrm{~ms}^{-1}\right)$, a specific prismatic geometry was chosen with dimension $1.5^{*} 14 \mathrm{~mm}^{2}$ (Figure 1). Using this geometry, the aerodynamic stress, estimated around 1.5 $\mathrm{kPa}$, can be neglected in front of the tensile creep stress $(\approx 140$ $\mathrm{MPa})$.

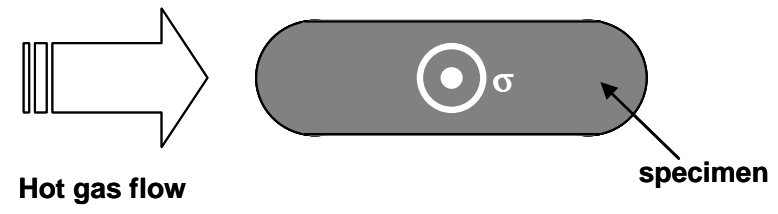

testing section

Figure 1. Schematic illustration of the testing section of the STR in top view. The prismatic geometry is chosen to limit the specimen drag in the gas flow. The centered circle indicates the stress axis.

Up to this point, the STR simulates a turboshaft engine in terms of temperature (up to $1230^{\circ} \mathrm{C}$ ), heating and cooling rates (up to $60^{\circ} \mathrm{C} / \mathrm{s}$ ), and environment (kerosene burnt gas). It is therefore able to perform well-controlled non-isothermal creep tests with reasonably fast heating rates to be representative of OEI conditions. However, due to technical limitations, the STR can sustain only few hours at $1050^{\circ} \mathrm{C}$ while a typical creep test in these conditions last at least $500 \mathrm{~h}$. The STR is therefore only used to perform the OEI simulation. Both pre-OEI $\left(\mathrm{t}_{\text {pre }}\right)$ and post-OEI $\left(t_{\text {post }}\right)$ creep at $1050^{\circ} \mathrm{C}$ are performed using a classical creep rig equipped with a radiant furnace using a special procedure including rigorous thermal control, developed to ensure the reliability of the non-isothermal creep tests. At the end of the preOEI creep, the material is cooled down under load to avoid any evolution of the deformation microstructure. The specimen is then loaded in the STR. The testing procedure during the OEI consists of: (1) ignition of the flame to reach $1050^{\circ} \mathrm{C}$ after few seconds, (2) applying a tensile stress $\sigma_{0}+\Delta \sigma$ to the specimen at $1050^{\circ} \mathrm{C}$ for $1 \mathrm{~min}$ (3) performing a jump from $1050^{\circ} \mathrm{C}$ to $1200^{\circ} \mathrm{C}$ by increasing the pressure of injection of kerosene and maintaining this regime for durations ranging 30 s to $150 \mathrm{~s}$, (4) cooling the material down at room temperature at $60^{\circ} \mathrm{C} / \mathrm{s}$ under load to preserve the deformation microstructure developed during the OEI. At this step, the specimens gauge lengths are systematically measured to deduce the plastic strain cumulated during the OEI simulation. Finally, the material is reloaded in the classical creep rig for the post-OEI creep until failure. Special care was taken to control the thermal conditions at the beginning of this last stage in order to limit the microstructure evolutions possibly occurring during the temperature stabilization.

\section{Material and specimens}

MC2 is a second generation nickel-based superalloy developed by ONERA for gas turbine applications operating at high temperature $\left(\mathrm{T}>900^{\circ} \mathrm{C}\right.$ ). Its weight composition is given in Table 1 . Asgrown material was solution heat treated at $1305^{\circ} \mathrm{C}$ for 3 hours and air quenched, to dissolve all the $\gamma^{\prime}$ phase particles formed by eutectic reaction during solidification and to reduce chemical segregations. It was then aged for $6 \mathrm{~h}$ at $1080^{\circ} \mathrm{C}$ and air quenched followed by $20 \mathrm{~h}$ at $870^{\circ} \mathrm{C}$ and air quenched to control both the $\gamma$ ' size $(\approx 0.4 \mu \mathrm{m})$ and to achieved the best creep resistant microstructure i.e. $\gamma^{\prime}$ content around $70 \%$ in volume (Figure 2). This microstructure will be called the as-received state of the 
material. Creep specimens, $14 \mathrm{~mm}$ gauge length with a prismatic section $4 \mathrm{~mm}$ wide and $1.5 \mathrm{~mm}$ thick, were machined from single crystal rods with orientation within $5^{\circ}$ off [001] along the strain axis, secondary orientation being both parallel to the gauge side and perpendicular to the gauge axis (see Figure 1).

\begin{tabular}{|c|c|c|c|c|c|c|c|c|}
\hline Element & $\mathrm{Ni}$ & $\mathrm{Cr}$ & $\mathrm{Co}$ & $\mathrm{W}$ & $\mathrm{Ta}$ & $\mathrm{Al}$ & $\mathrm{Mo}$ & $\mathrm{Ti}$ \\
\hline $\mathrm{Wt} \%$ & $\mathrm{Bal}$ & 8 & 8 & 8 & 6 & 5 & 2 & 1.5 \\
\hline
\end{tabular}

Table 1. MC2 nominal composition.

\section{Microstructure characterizations}

Microstructure evolutions occurring during non-isothermal creep were performed on dedicated specimens, by interrupting the tests either at the end of the pre-OEI creep or just after an OEI or in the course of the post-OEI creep test. A JEOL JSM 7000F scanning electron microscope (SEM) operating in the range $9-25 \mathrm{kV}$ was used to observed the microstructure evolution. SEM samples were mechanically polished until a mirror finish was obtained. Selective dissolution of the $\gamma$ phase by electrochemical polishing of the surface using a triacid solution (vol. \%) $45 \% \mathrm{H}_{2} \mathrm{SO}_{4}, 42 \%$ $\mathrm{HNO}_{3}$ and $13 \% \mathrm{H}_{3} \mathrm{PO}_{4}$ was then performed to reveal details of the $\gamma / \gamma$ ' microstructure. Dislocation substructures were analyzed using a Philips CM 20 transmission electron microscope (TEM) operating at $200 \mathrm{kV}$. TEM samples were cut perpendicularly to the strain axis $<001>$ corresponding to the dislocations habit plane. Cell sizes of the dislocation networks were estimated by measuring the mean diameter of dislocation cells inscribed circles. The average cell size results from at least 200 measures.

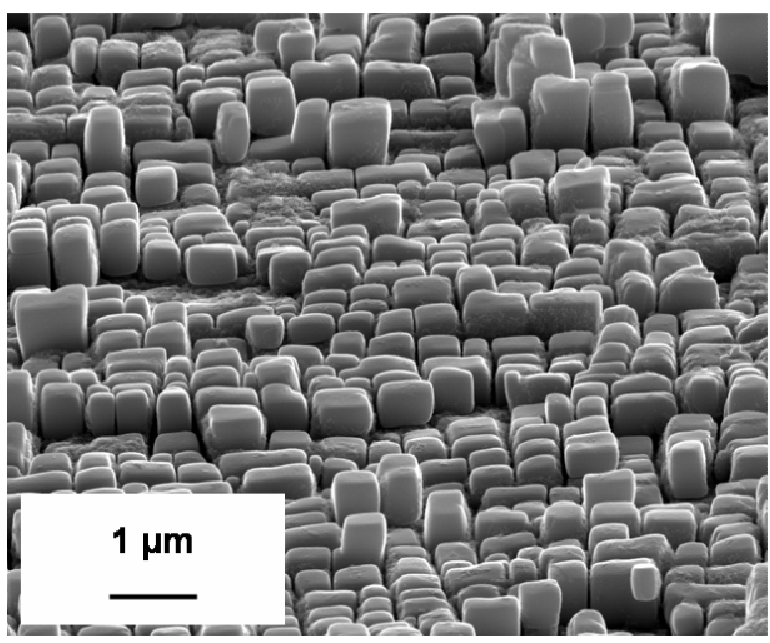

Figure 2. As-treated $\gamma / \gamma^{\prime}$ microstructure of MC2 alloy (tilted at $\left.70^{\circ}\right)$.

\section{Experimental results}

\section{Non-isothermal creep behavior}

Typical non-isothermal creep behavior corresponding to the OEI simulation is represented in Figure 3. In this example, the first part of the creep curve corresponds to $t_{\text {pre }}=100 \mathrm{~h}$ and is analog to the typical isothermal behavior at $1050^{\circ} \mathrm{C} / 140 \mathrm{MPa}$. At the end of $t_{\text {pre }}$, the simulation of the OEI lasted for $t_{\mathrm{OEI}}=150 \mathrm{~s}$. Surprisingly, the post-OEI creep stage $t_{\text {post }}\left(1050^{\circ} \mathrm{C} / 140 \mathrm{MPa}\right)$, exhibits the typical primary, steady-state and tertiary stages. As for isothermal conditions, once the tertiary stage is initiated, the material fails rapidly. Therefore, this stage will be neglected in the following, since it is far beyond useful application of the material. As a conclusion, the OEI is not "too harmful" since neither failure nor massive plastic strain were observed during or just after it and the material could sustain post-OEI creep for hours before failure.

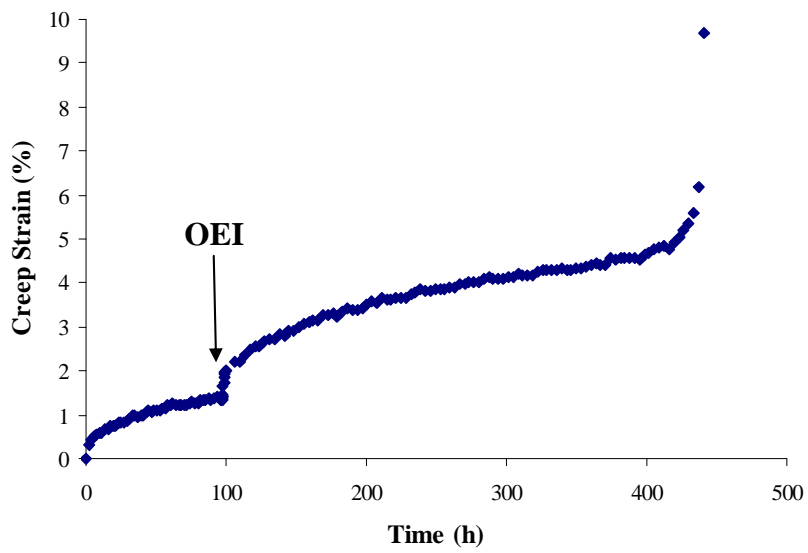

Figure 3. Non-isothermal creep behavior with $\mathrm{t}_{\text {pre }}=100 \mathrm{~h}$ and $\mathrm{t}_{\mathrm{OEI}}$ $=150 \mathrm{~s}$.

From Figure 3, as a first striking result, the material can sustain a much higher deformation amplitude at the end of the post-OEI steady-state creep stage than that possibly achieved in pure isothermal conditions i.e. 1\% approximately [15]. As a second striking result, the material deforms for the same amount of strain (approximately 1\%) during the post-OEI steady-state creep life but the primary amplitude increases along with $\mathrm{t}_{\mathrm{OEI}}$ (see for example Figure 4). These results are true for any $t_{\mathrm{OEI}}$ and any $\mathrm{t}_{\mathrm{pre}}$. As a consequence, longer $t_{\mathrm{OEI}}$ leads to larger overall plastic strain than shorter $t_{\mathrm{OEI}}$, solely due to the very large difference in postOEI primary creep amplitude. In other words, the OEI softens the material i.e. it can sustain much higher strain amplitude than what could have been reached in pure isothermal conditions because of a larger plastic strain during the post-OEI creep life.

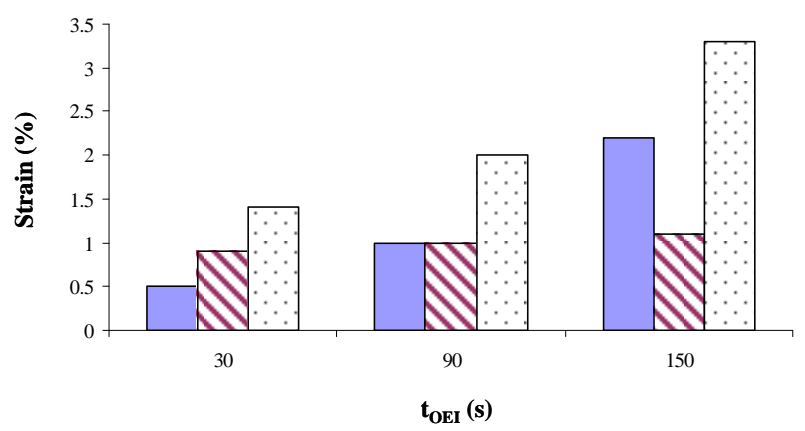

Figure 4. Comparison between strains in the various stages of post-OEI creep for different $\mathrm{t}_{\mathrm{OEI}}$. (Grey bar: primary creep stage; Striped bar: steady-state; Dotted bar: total deformation at the tertiary onset). Steady-state strains are identical for any $\mathrm{t}_{\mathrm{OEI}}$.

Figure 5 plots the evolution of the logarithm of the strain rate against time for non isothermal creep tests with various $t_{\mathrm{OEI}}$. 
According to Figure 5, the strain rate of the post-OEI steady-state is accelerated compared to its pre-OEI (i.e. pure isothermal) counterpart. As a third striking result, longer $t_{\mathrm{OEI}}$ leads to slower post-OEI steady-state strain rate. For example, the post-OEI minimum creep rate is $\dot{\varepsilon}_{\min -150 \mathrm{~s}}=1.8 * 10^{-8} \mathrm{~s}^{-1}$ after $\mathrm{t}_{\mathrm{OEI}}=150 \mathrm{~s}$ while it is twice as fast e.g. $\dot{\varepsilon}_{\min -30 \mathrm{~s}}=3.6^{*} 10^{-8} \mathrm{~s}^{-1}$ after $\mathrm{t}_{\mathrm{OEI}}=$ $30 \mathrm{~s}$. As a consequence, longer $\mathrm{t}_{\mathrm{OEI}}$ always leads to longer postOEI residual creep lives $t_{\text {post }}$ except for $t_{p r e}=0$. This result derives simply from the fact that the time needed to reach the same amount of post-OEI steady-state strain (e.g. 1\%) is shorter with faster strain rate. In the case of $t_{\text {pre }}=0$, as a fourth striking result, $\mathrm{t}_{\mathrm{OEI}}$ has no effect on both the overall creep life and steady-state creep rate, which are surprisingly identical to those in pure isothermal condition. However, in this condition, the OEI on asreceived material still softens it since the overall strain at the end of the steady-state is larger than that measured for isothermal conditions.

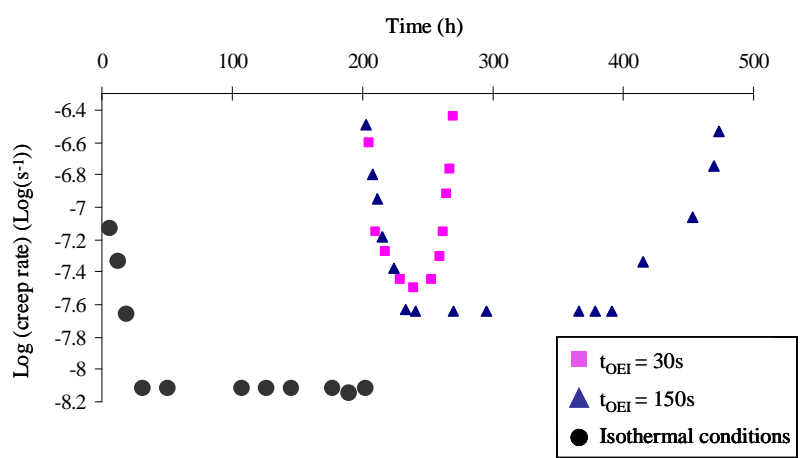

Figure $5 . \log (\dot{\varepsilon})$ vs time. Longer $\mathrm{t}_{\mathrm{OEI}}$ leads to slower minimum strain rate than a shorter one. Both are faster than isothermal minimum creep strain rate

\section{$\underline{\text { Microstructure evolutions }}$}

Microstructure modifications occurring in the course of nonisothermal creep tests were analyzed after interrupting the test at the end of $t_{\text {pre }}$, just after the simulation of the OEI or after some time spent in $t_{\text {post }}$. Figure 6 shows examples of the effect of an OEI (with $\mathrm{t}_{\mathrm{OEI}}=90 \mathrm{~s}$ or $150 \mathrm{~s}$ ) performed after $\mathrm{t}_{\text {pre }}=50 \mathrm{~h}$, corresponding to a fully rafted microstructure. Starting from a $\gamma^{\prime}$ raft area fraction $\mathrm{f}_{\gamma^{\prime}}$ close to $60 \%$ at the end of $\mathrm{t}_{\text {pre }}$ (Figure 6a), the overheating at $1200^{\circ} \mathrm{C}$ produces massive $\gamma$ ' dissolution, especially for longer $\mathrm{t}_{\mathrm{OEI}}$ (Figure $6 \mathrm{~b}, \mathrm{c}$ ). In this case, $\mathrm{f}_{\gamma^{\prime}}$ can be as low as $35 \%$ (Figure 6c). Along with the rafts dissolution, the matrix channels grow larger, their width increasing approximately from $200 \mathrm{~nm}$ to $500 \mathrm{~nm}$ with increasing $\mathrm{t}_{\mathrm{OEI}}$. However, in agreement with literature [16-19], the supersaturated $\gamma$ matrix channels fill up with fine $\gamma^{\prime}$ cubic precipitates upon cooling just after the OEI (see [14, 15] for illustrations of this hyperfine reprecipitation in case of non-isothermal creep). After subsequent post-OEI creep, both original $\mathrm{f}_{\gamma^{\prime}}$ and $\gamma$ channel width are recovered, so that the initial microstructure is rebuilt. No small $\gamma^{\prime}$ precipitates remain in the matrix channel (Figure 6d).

Along with the $\gamma^{\prime}$ raft evolution, the dislocation networks located at the $\gamma / \gamma^{\prime}$ interface evolve as well. Figure 7 represents the evolution of the dislocation networks during non-isothermal creep. Figure 7a shows the typical dislocation networks developed during isothermal conditions at $1050^{\circ} \mathrm{C} / 140 \mathrm{MPa}$ during secondary creep stage. Figures $7 \mathrm{~b}$ to $7 \mathrm{~d}$ show the dislocation networks after various overheating times. By measuring the dislocation cell sizes, it appears that the OEI provokes an increase of cell size for any $t_{\mathrm{OEI}}$ compared to the cell size measured after isothermal creep. However, longer $t_{\mathrm{OEI}}$ leads to smaller cell size along with a smaller standard deviation. No large evolution of the cell size was noticed during post-OEI creep. It is only slightly reduced but never reaches the pre-OEI value.

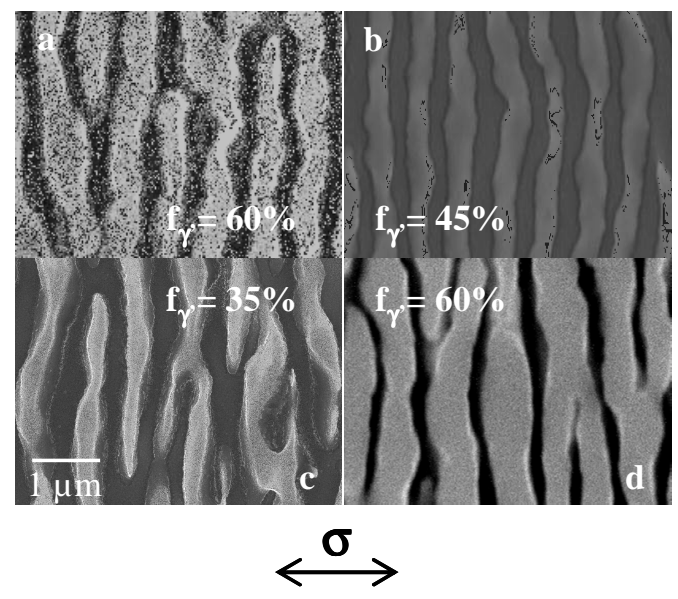

Figure 6 Evolution of the $\gamma^{\prime}$ rafts during non isothermal creep ( $\gamma^{\prime}$ rafts are in light grey) a) raft microstructure after $t_{\text {pre }}=50 \mathrm{~h}$ at $\left.1050^{\circ} \mathrm{C} / 140 \mathrm{MPa}, \mathrm{b}\right)$ raft microstructure after $\mathrm{t}_{\text {pre }}=50 \mathrm{~h}+\mathrm{t}_{\mathrm{OEI}}=$ $90 \mathrm{~s}, \mathrm{c})$ raft microstructure after $\left.\mathrm{t}_{\text {pre }}=50 \mathrm{~h}+\mathrm{t}_{\mathrm{OEI}}=150 \mathrm{~s}, \mathrm{~d}\right) \mathrm{raft}$ microstructure after $\mathrm{t}_{\text {post }}=142 \mathrm{~h}$

\section{Non isothermal creep modeling}

\section{$\underline{\text { Modeling microstructural evolutions }}$}

Viscoplastic behavior of single crystal superalloys are usually modeled using constitutive equations which account for the effects of the applied stress $\sigma_{0}$ and of several damaging mechanisms (such as increase of pore density, oxidation, increase of mobile dislocations, precipitates coarsening ...) [7, 20]. Temperature dependence of the viscoplastic behavior is only described through the evolution of the material's constants used in these laws. These constants have to be identified for each temperature of interest.

A classical approach to describe creep is the Chaboche law [21]. This approach gives the evolution of the creep strain rate $\dot{\varepsilon}_{p}$ using the concept of internal stress $\sigma_{i}$ (Eq. 1).

$$
\dot{\varepsilon}_{\mathrm{p}}=\left(\frac{\left|\sigma_{0}-\mathrm{X}\right|-\mathrm{R}-\mathrm{R}_{0}}{\mathrm{~K}}\right)^{\mathrm{n}} \operatorname{Sgn}\left(\sigma_{0}-\mathrm{X}\right)
$$

In this equation, the internal stress $\left(\sigma_{i}=X+R+R_{0}\right)$ is the sum of isotropic and kinematic hardenings, respectively $R$ and $X$ (null at the beginning of the mechanical loading) and of $\mathrm{R}_{0}$ the initial internal stress considered as isotropic. $\mathrm{K}$ and $\mathrm{n}$ are mechanical constants depending on both the temperature and the mechanical loading $\sigma_{0}$. 

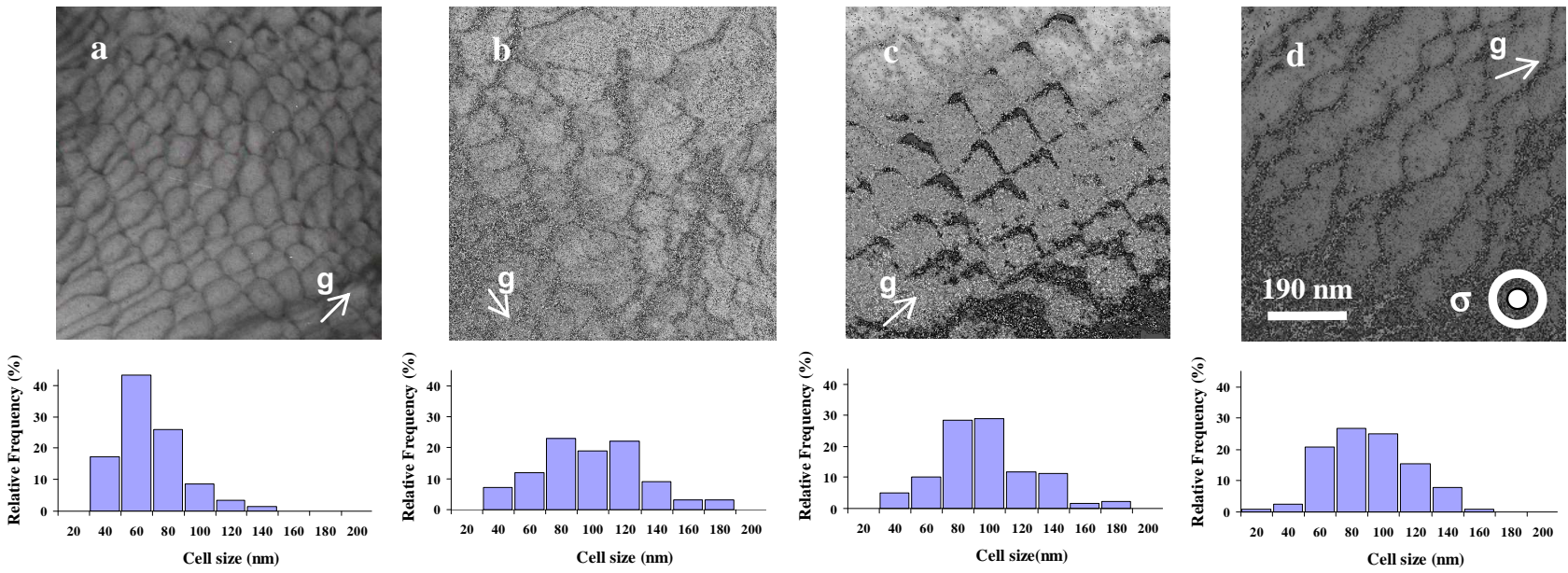

Figure 7. TEM bright field ( $\mathrm{g}=002, \mathbf{B}=[001])$ illustrating the evolution of the dislocation networks cell morphology at the $\gamma / \gamma$ ' interfaces and their corresponding bar charts representing the cell size distribution for a) isothermal conditions during secondary creep stage b) after $\left.\mathrm{t}_{\mathrm{OEI}}=30 \mathrm{~s} \mathrm{c}\right)$ after $\left.\mathrm{t}_{\mathrm{OEI}}=90 \mathrm{~s} \mathrm{~d}\right)$ after $\mathrm{t}_{\mathrm{OEI}}=150 \mathrm{~s}$.

For the description of the uniaxial creep strain along a particular direction of a single crystal (the [001] orientation in our case), a simpler form of equation 1 can be used by removing the kinematic hardening X, keeping only isotropic hardening R. A nonlinear form of $\mathrm{R}$ is chosen with an exponentially saturating function (Eq. 2) of the cumulated creep strain in order to describe the relatively long secondary creep regimes (regardless of creep lives) of single crystal Ni-based superalloys at high temperature $\left(\mathrm{T}>1000^{\circ} \mathrm{C}\right)$ and low stress [4]. This formulation of isotropic hardening accounts for the fact that throughout the primary creep regime, strain hardening gradually increases due to the combined effects of dislocation motion in the matrix corridors (work hardening) and $\gamma^{\prime}$ precipitate rafting [22, 23]. Saturation of $\mathrm{R}$ attests for creep steady-state. It corresponds to an equilibrium value of the dislocation density in the matrix channels of superalloys [24]. At this point, the creep behavior of the material is mainly dominated by recovery processes such as dislocation climb along $\gamma / \gamma^{\prime}$ interfaces of the rafted structures or $\gamma$ ' cutting by dislocations, which was recently identified as creep rate controlling in Recontaining superalloys [25, 26].

$$
\dot{\mathrm{R}}=\mathrm{b}(\mathrm{Q}-\mathrm{R}) \dot{\varepsilon_{\mathrm{p}}}
$$

Starting from this classical formalism for isothermal creep modeling, it was chosen to modify it for non-isothermal creep since an OEI produces transient microstructure evolutions. In these conditions, equations 1 and 2 with parameters identified for $1050^{\circ} \mathrm{C}$ and $1200^{\circ} \mathrm{C}$, the temperatures reached during nonisothermal creep, are useless since these constants will only be representative of the equilibrium creep conditions. It was therefore chosen to introduce new internal variables and hardening (softening) in the isothermal creep behavior to attest for the microstructure evolutions during overheatings which allows the model to capture transients in the mechanical behavior.

The principle of this model, based on pioneering works on high temperature fatigue of IN100 superalloy [27], consists of the quantification of microstructure deviation from the equilibrium with time. Two main features were identified to control the nonisothermal creep behavior:

- the evolution of $f_{\gamma^{\gamma}}$, the volume fraction of $\gamma^{\prime}$-strengthening phase during and after the OEI simulation

- the evolution of the dislocation structures at $\gamma / \gamma^{\prime}$ interfaces

As shown in the experimental section, dissolution of the $\gamma^{\prime}$ phase softens the material. Therefore, it can be assumed that the progressive recovery of its $\gamma^{\prime}$ phase equilibrium value $\mathrm{f}_{\mathrm{eq}}$ hardens it. In this context, the deviation of $\mathrm{f}_{\gamma^{\prime}}$ from its equilibrium $\mathrm{f}_{\mathrm{eq}}$ in the vicinity of overheatings can be seen as a variation of the yield strength of the material. In order to account for macroscopic softening/hardening effects, the internal variable $R^{*}$ was introduced in equation 1. Furthermore, kinematic hardening in equation 1 is still neglected since it is assumed that both $\gamma^{\prime}$ phase dissolution and precipitation is isotropic. The variation of creep strain rate for non-isothermal creep can be written as follows:

$$
\dot{\varepsilon}_{\mathrm{p}}=\left(\frac{\sigma_{0}-\mathrm{R}-\mathrm{R}_{0}-\mathrm{R}^{*}}{\mathrm{~K}}\right)^{\mathrm{n}}
$$

Since the macroscopic hardening/softening is linked with the deviation of $\mathrm{f}_{\gamma^{\prime}}$ from its equilibrium value $\mathrm{f}_{\text {eq }}$, it is assumed that $\mathrm{R}^{*}$ directly depends on $\mathrm{f}_{\gamma^{\prime}}$, the $\gamma^{\prime}$-volume fraction at any time (Eq. 4):

$$
\stackrel{\bullet}{\mathrm{R}^{*}}=-\frac{\mathrm{R}^{*}}{\tau_{\mathrm{r}}}+\alpha\left(\mathrm{f}_{\gamma^{\prime}}-\mathrm{f}_{\mathrm{eq}}\right)
$$

where

$$
\stackrel{\bullet}{\mathrm{f}_{\gamma^{\prime}}}=\frac{\mathrm{f}_{\text {eq }}-\mathrm{f}_{\gamma^{\prime}}}{\tau}
$$

In these equations, $\mathrm{f}_{\mathrm{eq}}$ is the $\gamma^{\prime}$-volume fraction at equilibrium at the tested temperatures equal to 0.6 and 0.3 at $1050^{\circ} \mathrm{C}$ and $1200^{\circ} \mathrm{C}$, respectively [12]. $\tau$ is a thermodynamic time constant 
being equal to $\tau_{\mathrm{d}}$, characteristic of the dissolution of the $\gamma^{\prime}$-phase on heating the material at $1200^{\circ} \mathrm{C}$ under load, and $\tau_{\mathrm{r}}$, characteristic of the recovery of the $\gamma^{\prime}$-microstructure by precipitation and coalescence processes when back at $1050^{\circ} \mathrm{C}$. Based on data available in the literature $[12,28]$, the dissolution time constant $\tau_{\mathrm{d}}$ and the $\gamma^{\prime}$-recovery time constant $\tau_{\mathrm{r}}$ used in equation 5 were determined: $\tau_{\mathrm{d}}$ was actually measured for cubic and rafted $\gamma^{\prime}$ microstructure while $\tau_{\mathrm{r}}$ was only measured in case of rafted structure $[12,15,28]$.

As observed in the experimental section, the dislocation networks are modified by the OEI and can be seen as recovery. In this context, a recovery function $g=b_{v}\left(Q_{v}-R\right)$ was introduced in the isotropic hardening $R$ (Eq. 2) to model the effects of the dislocation structure evolutions. This results in equation 7 .

$$
\dot{\mathrm{R}}=\mathrm{b}(\mathrm{Q}-\mathrm{R}) \dot{\varepsilon_{\mathrm{p}}}+\mathrm{b}_{\mathrm{v}}\left(\mathrm{Q}_{\mathrm{v}}-\mathrm{R}\right)
$$

Such a modeling approach is usually chosen to describe the evolution in creep properties of aged superalloys where, for example, precipitates sizes can increase by Ostwald ripening processes [29, 30]. In our case, the function $\mathrm{g}$ attests for modification of dislocation networks at the $\gamma / \gamma^{\prime}$ interface after an OEI has occurred.

\section{$\underline{\text { Modeling identification and results }}$}

Isothermal identifications of the behavior of the material at $1050^{\circ} \mathrm{C}$ and $1200^{\circ} \mathrm{C}$ (e.g: $\mathrm{n}, \mathrm{K}, \mathrm{Q}, \mathrm{b}, \mathrm{R}_{0}$ parameters of equations 1 and 2) have been carried out using results extracted from tensile tests conducted under different strain rates to enhance the viscoplastic behavior [28]. A step by step optimization comparing numerical simulation with a given set of parameters to experimental results was conducted using the optimizer module of the finite element code Zebulon.

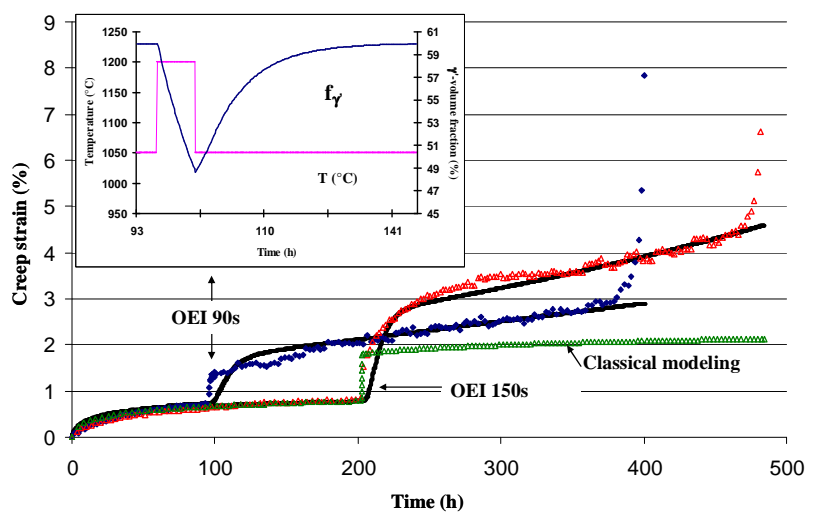

Figure 8. Modeling of the non-isothermal creep behavior (bold lines) for a 90s OEI (respectively a $150 \mathrm{~s}$ OEI) introduce at $\mathrm{t}_{\mathrm{pre}}=$ $98 \mathrm{~h}$ (resp. $\mathrm{t}_{\mathrm{pre}}=200 \mathrm{~h}$ ) and compared to their respective experimental curves (dotted lines). The evolutions of the $\gamma^{\prime}$ volume fraction $\left(\mathrm{f}_{\gamma^{\prime}}\right)$ and of the temperature $\left(\mathrm{T}^{\circ} \mathrm{C}\right)$ as a function of a non-linear scaled time in the case of the 90s OEI is given as an insert. For sake of comparison, modeled creep curve with a classical approach is given in the case of the 150s OEI.
In case of non-isothermal conditions, new parameters $\tau_{\mathrm{d}}, \tau_{\mathrm{r}}$ and $\mathrm{f}_{\mathrm{eq}}$ were directly determined from microstructure observations [12, 15] while the parameters $\alpha, b_{v}$ and $Q_{v}$ have been optimized from a wide range of non-isothermal creep tests, such as the one presented in Figure 3, with different $\mathrm{t}_{\mathrm{pre}}$ and $\mathrm{t}_{\mathrm{OEI}}$.

Figure 8 illustrates two results of the non-isothermal modeling compared with the experimental results. There is excellent agreement between modeled and experimental curves for each case, with post-OEI primary creep regimes and increased stationary creep strain rates well described. Predictions from the classical modeling using equations 1 and 2 with their respective constants at $1200^{\circ} \mathrm{C}$ during the $\mathrm{OEI}$ and at $1050^{\circ} \mathrm{C}$ during the rest of the non-isothermal creep life, show a great departure from the experimental curve, especially during post-OEI creep were microstructure has evolved. Indeed, as these materials' constants were identified in isothermal conditions, they may not be representative of these evolutions presented in previous sections of this article. Therefore, such a modeling approach provides a real breakthrough for the prediction of material deformation under non-isothermal conditions inducing microstructural changes.

\section{Discussion}

During isothermal creep at high temperature/low stress, it is generally accepted that the primary creep stage ends when the rafting process is completed and dislocations networks at the $\gamma / \gamma^{\prime}$ interfaces are well established [5, 22, 23, 31]. However, in the case of non-isothermal conditions, a primary creep stage is systematically observed at the beginning of post-OEI creep whether the microstructure is built with $\gamma^{\prime}$ cubes $\left(t_{\text {pre }}=0\right)$ or with $\gamma^{\prime}$ rafts with well-developed dislocations networks at the $\gamma / \gamma^{\prime}$ interfaces. The rafting process can therefore be ruled out for being directly involved during the post-OEI primary creep stage. However, as observed in Figure 6, massive dissolution of the $\gamma$ ' phase occurs during the $\mathrm{OEI}$ simulation at $1200^{\circ} \mathrm{C}$, promoting the widening of the $\gamma$ matrix channels. During post-OEI creep, the equilibrium $\gamma^{\prime}$ volume fraction $\mathrm{f}_{\mathrm{eq}}$ at $1050^{\circ} \mathrm{C}(60 \%)$ is recovered after few hours. Based on the results given by the model, it is seen that a simple approach, in terms of a temporarily deviation of $f_{\gamma^{\prime}}$ from $\mathrm{f}_{\mathrm{eq}}$ due to the OEI, reproduces fairly well the new post-OEI primary creep stage (see insert Fig. 8). According to the model, the post-OEI primary stage lasts for approximately the time needed to recover $\mathrm{f}_{\mathrm{eq}}$ at $1050^{\circ} \mathrm{C}$. At a microscopic level, the OEI simulation reduces temporarily the Orowan stress $\sigma_{\text {or }}$ along with the transient modification of $\mathrm{f}_{\gamma}$, over the time necessary for both $\gamma^{\prime}$ rafts and $\gamma$ channels to recover their initial width during the post-OEI creep at $1050^{\circ} \mathrm{C}$. Indeed, to propagate into the $\gamma$ channels, dislocations need to overcome the Orowan stress [32, 33]:

$$
\sigma_{\text {or }}=\sqrt{\frac{2}{3}} \frac{\mu \times b}{w}
$$

where $\mu$ is the shear modulus, $\mathrm{b}$ is the Burgers vector and $\mathrm{w}$ is the channel width. In this context, a large plastic deformation is expected at the beginning of the post-OEI creep stage since larger $\gamma$ channels (increase of $\mathrm{w}$ ) allow easier matrix dislocation motion due to a drop of $\sigma_{\text {or }}$. This should even be enhanced for longer $t_{\mathrm{OEI}}$. However, the deformation rate will eventually slow down along with the recovery of $f_{\text {eq }}$. In this context, longer primary 
stage results from larger deviation from $\mathrm{f}_{\mathrm{eq}}$ caused by longer $\mathrm{t}_{\mathrm{OEI}}$. It seems therefore reasonable to assume that the primary creep stage is closely linked to the deviation from $f_{e q}$ for a given temperature at the microscopic level. The amplitude may also be closely linked to the diffusion kinetics of chemical elements in the material to rebuild the pre-OEI microstructure.

During the isothermal steady-state creep stage at high temperature/low stress, the microstructure is built with stable $\gamma$ rafts and well-developed dislocation networks at the $\gamma / \gamma^{\prime}$ interfaces. At a microscopic level, an internal stress $\sigma_{\mathrm{i}}$ builds up in the $\gamma$ channels, and can be described as follows:

$$
\sigma_{\mathrm{i}}=\sigma_{\mathrm{sol}-\mathrm{sol}}+\sigma_{\mathrm{bs}}+\sigma_{\mathrm{or}}
$$

where $\sigma_{\text {sol-sol }}$ is the solid solution hardening, $\sigma_{\mathrm{bs}}$ is the back stress induced by dislocation networks and $\sigma_{\text {or }}$ is the Orowan stress due to the $\gamma^{\prime}$ rafts. It was reported in literature that under isothermal high temperature/low stress conditions, only a limited number of matrix dislocations can enter the $\gamma$ channel due to $\sigma_{\mathrm{bs}}$ [34], and that further deformation is only possible if dynamic recovery of these matrix dislocations occurs by $\gamma^{\prime}$ cutting events $[26,35,36]$. It was suggested by these authors that the minimum creep rates $\dot{\varepsilon}_{\text {min }}$ directly result from the number of $\gamma$ ' cutting events. As a result, for isothermal conditions, a stress increase leads to faster $\dot{\varepsilon}_{\min }$. The problem is that in our case, the applied stress remains constant throughout the test and post-OEI $\dot{\varepsilon}_{\text {min }}$ may vary depending on both $t_{\mathrm{OEI}}$ and $\mathrm{t}_{\text {pre }}$. However, as proposed in the model, the recovery function $\mathrm{g}$ has to be introduced in order to describe the post-OEI steady-state stage. This recovery function attests directly for a larger dislocation activity in the matrix channels according to [34]. As a first assumption, it can be postulated that the OEI simulation results in a virtual increase of the applied stress in post-OEI creep. Actually, this would explain satisfactorily the increase of post-OEI $\dot{\varepsilon}_{\text {min }}$ when the OEI is performed on a microstructure built with rafts. However, this fails to explain the behavior when the OEI is performed on as-received material, where $\dot{\varepsilon}_{\min }$ remains the same as in isothermal conditions. Therefore, this first assumption can be ruled out. As a second assumption, the OEI may modify the internal stress $\sigma_{i}$ of the material as proposed in the model section, where $\mathrm{R}_{0}$, in equation 3 , corresponds to $\sigma_{\text {sol-sol }}$. Since an OEI performed on as-received material does not modify $\dot{\varepsilon}_{\min }$ compared to its pure isothermal counterpart, it can be assumed that both terms $\sigma_{\text {or }}$ and $\sigma_{\text {sol-sol }}$ in equation 9 are hardly affected by an OEI, at least after that $f \gamma^{\prime}$ recovers its equilibrium $\mathrm{f}_{\mathrm{eq}}$. It is therefore assumed that OEIs may only greatly impact $\sigma_{b s}$, the backstress resulting from the dislocations in the matrix channels. As shown in the experimental result section, shorter $\mathrm{t}_{\mathrm{OEI}}$ leads to larger dislocation cell sizes irregularly distributed i.e. lower dislocation density at the $\gamma / \gamma^{\prime}$ interfaces. This probably derives from the fact that for longer time spent at $1200^{\circ} \mathrm{C}$, the microstructure gets closer to its equilibrium at this temperature. In this context, it is assumed that the internal stress is smaller for shorter $t_{\mathrm{OEI}}$, allowing more dislocations to enter the $\gamma$ matrix channels during subsequent creep at $1050^{\circ} \mathrm{C}$. According to previous studies $[26,35,36]$, this leads to an increased minimum strain rate. This assumption is also in full agreement with the experimental results obtained for an OEI performed at $t_{\text {pre }}=0$, where minimum creep rates do not depend on $\mathrm{t}_{\mathrm{OEI}}$. In this case, the microstructure exhibits neither $\gamma^{\prime}$ rafts nor dislocation networks at the $\gamma / \gamma^{\prime}$ interfaces and $\sigma_{\mathrm{i}}$ reduces simply to the sum of $\sigma_{\text {sol-sol }}+\sigma_{\text {or }}$. In this context, $\sigma_{\mathrm{i}}$ should not be substantially modified by the OEI. This is also well predicted by the model [37], for this condition $\left(t_{\text {pre }}=0\right)$ which was not used as an input for the identification of the model parameters.

\section{Conclusion}

The non-isothermal creep behavior of $\mathrm{MC} 2$ single crystal Nibased superalloy was studied in conditions representative of inservice One Engine Inoperative (OEI) events possibly encountered on turboshaft engines for helicopters. Overheatings at $1200^{\circ} \mathrm{C}$ under load were introduce in the course of the creep life of the material at $1050^{\circ} \mathrm{C}$ using a burner rig especially adapted for the purpose of these experiments, enabling temperature jumps as fast as $60^{\circ} \mathrm{C} / \mathrm{s}$. The main consequences of such temperature jumps under these thermal and mechanical conditions are:

- a decrease of the overall creep life of the material.

- a modification of the creep behavior with a new primary regime right after the OEI and an increase of the post-OEI stationary creep rate compared to that before.

The experimental results show that an OEI simulation modifies the primary creep amplitude compared to its isothermal counterpart, independently of the microstructure of the material. This amplitude increases with increasing the OEI duration $t_{\mathrm{OEI}}$. OEI simulation also modifies the minimum creep rate which is increased compared to isothermal conditions. In addition, these minimum creep rates depend on $\mathrm{t}_{\mathrm{OEI}}$ in a surprising way: longer $t_{\mathrm{OEI}}$ leads to slower minimum creep rates if the OEI is performed on a fully rafted microstructure. If OEIs are performed on asreceived material, minimum creep rates equal the ones measured for isothermal conditions. Finally, the plastic deformation at the onset of the tertiary stage depends solely on the primary stage amplitude, steady-state stage deformation amplitude being constant.

This non-isothermal creep behavior was clearly shown to be dependant on both the dissolution/precipitation/coalescence of the $\gamma$-phase during overheatings for the new primary creep regime, and on the modification of the dislocation density at the $\gamma / \gamma^{\prime}$ interfaces for the post-OEI secondary creep regime.

Based on these microstructural evolutions, a viscoplastic Chaboche law was modified by introducing two new internal variables, for the evolutions of the $\gamma^{\prime}$ phase volume fraction, and by adding a recovery function, for the evolution of the dislocation density. This model is predictive of the creep strains encountered during non-isothermal creep until the transitions with the tertiary regime, whatever the OEI length and position in the creep life at $1050^{\circ} \mathrm{C}$ of the material.

\section{Acknowledgements}

The authors gratefully acknowledge Turboméca -SAFRAN group and la DGA for financial support. We especially thank Professor G. Cailletaud for judicious advices in modeling approaches, Dr J.L. Champion and Dr P. Villechaise for their help in several experiments. 


\section{References}

1. F. Lubahn, Plasticity and Creep of metals (New York: Wiley, 1968).

2. D. Fournier. "Acquis, Besoins, Espoirs", (Paper presented at Colloque National Superalliages Monocristallins, Toulouse, 1995), 7.

3. M. Benyoucef et al., "In situ deformation experiments on a $\gamma / \gamma^{\prime}$ superalloy - Strengthening mechanisms", Materials Science and Engineering, A234-236 (1997), 692-694.

4. $\quad$ P. Caron. "High $\gamma^{\prime}$ solvus new generation nickel-based superalloys for single crystal turbine blade applications", (Paper presented at Superalloys 2000, Warrendale, PA, 2000), 737-746.

5. R.C. Reed et al., "Creep of CMSX-4 superalloy single crystals: effects of rafting at high temperature", Acta mater, 47 (12) (1999), 3367-3381.

6. N. Matan et al., "Creep of CMSX-4 superalloy single crystals: effects of misorientation and temperature", Acta mater, 47 (5) (1999), 1549-1563.

7. D.W. Maclachlan and D.M. Knowles, "Creep-behaviour Modelling of the Single-Crystal Superalloy CMSX-4", Metallurgical and Materials Transactions A, 31A (May) (2000), 1401-1411.

8. P. Caron et al., "On the effects of heat treatments on the creep behaviour of a single crystal superalloy", Scripta Metallurgica, 20 (6) (1986), 875-880.

9. G.L. Drew et al. "Single crystal superalloys: the transition from primary to secondary creep", (Paper presented at Superalloys 2004, Seven Springs, 2004), 127-136.

10. F. Diologent, "Comportement en fluage et en traction de superalliages monocristallins à base de nickel", (Ph.D. thesis, Université de Paris Sud, Centre d'Orsay, 2002).

11. D.W. Maclachlan and D.M. Knowles, "Modelling and prediction of the stress rupture behaviour of single crystal superalloys", Material Science and Engineering, A302 (2001), 275-285.

12. J. Cormier, X. Milhet, and J. Mendez, "Effect of very high temperature short exposures on the dissolution of the $\gamma$ ' phase in single crystal MC2 superalloy", Journal of Materials Science, 48 (18) (2007), 7780-7786.

13. T. Grosdidier, A. Hazotte, and A. Simon, "Precipitation and dissolution processes in $\gamma / \gamma$ ' single crystal nickel-based superalloys", Material Science and Engineering, A256 (1998), 183-196.

14. J. Cormier, X. Milhet, and J. Mendez, "Anisothermal Creep at very high temperature of a second generation Ni-based single crystal superalloy", Materials Science and Engineering, A483-484 (2008), 594-597.
15. J. Cormier, X. Milhet, and J. Mendez, "Non-isothermal creep at very high temperature of the Nickel based single crystal superalloy MC2", Acta Materialia, 55 (18) (2007), 6250-6259.

16. G.L. Erickson. "The development and application of CMSX-10", (Paper presented at Superalloys 1996, Warrendale, 1996), 35-44.

17. S. Duval et al., "Phase composition and chemical order in the single crystal base superalloy MC2", Acta Metall. Mater, 42 (1) (1994), 185-194.

18. K. Kakehi, "Influence of secondary precipitates and crystallographic orientation on the strength of single crystals of a Ni-based superalloy", Metallurgical and Materials Transactions A, 30A (May) (1999), 1249-1259.

19. A.M. Brass, D. Roux, and J. Chene, "Role of secondary $\gamma^{\prime}$ precipitation and of hydrogen in the first stage of the plastic deformation of the $\gamma$ matrix of a Ni base superalloy single crystal", Material Science and Engineering, A323 (2002), 97-102.

20. M. Mclean and B.F. Dyson, "Modelling the effects of damage and microstructural evolution on the creep behaviour of engineering alloys", Journal of engineering Materials and Technology, 122 (2000), 273-278.

21. J.-L. Chaboche, "Calcul des déformations viscoplastiques d'une structure soumise à des gradients thermiques évolutifs", (Ph.D. thesis, Orsay, 1972).

22. R.C. Reed, D.C. Cox, and C.M.F. Rae, "Damage accumulation during creep deformation of a single crystal superalloy at $1150^{\circ} \mathrm{C}^{\prime \prime}$, Materials Science and Engineering, A 448 (2007), 88-96

23. T. Sugui et al., "Aspects of primary creep of a single crystal nickel-base superalloy", Material Science and Engineering, A262 (1999), 271-278.

24. M. Probst-Hein, A. Dlouhy, and G. Eggeler, "Interface dislocations in superalloy single crystal", Acta Mater, 47 (8) (1999), 2497-2510.

25. G. Malzer et al., "Miniature specimen assessment of creep of the single crystal superalloys LEK 94 in the $1000^{\circ} \mathrm{C}$ temperature range", Metallurgical and Materials Transactions A, 38A (2007), 314-327.

26. A. Kostka et al., "L1 $1_{2}$-phase cutting during high temperature and low stress creep of a Re-containing Ni-base single crystal superalloy", Journal of Materials Science, 42 (2007), 3951-3957.

27. G. Cailletaud and J.-L. Chaboche. "Macroscopic description of the microstructural changes induced by varying temperature: example of the IN 100 cyclic behaviour", (Paper presented at Third International Conference on Mechanical Behaviour of Materials (ICM-3), Cambridge (G.B.), 1979). 
28. J. Cormier, "Comportement en fluage anisotherme à haute et très haute température du superalliage monocristallin MC2", (Ph.D. thesis, Université de Poitiers, 2006).

29. J. Lemaitre and J.L. Chaboche, Viscoplasticity Modelling of particular effects in Mechanics of Solid Materials (Cambridge: Cambridge University Press, 1990), 328.

30. J.-L. Chaboche and G. Cailletaud. "Loi de comportement en non-linéaire et exemples sur matériaux métalliques", (Paper presented at Journées à thème ADDL Fondements et implantation des lois de comportement élastoplastiques en éléments finis, Paris-Berçy, 2002).

31. J.X. Zhang et al., "The effect of lattice mismatch on the dislocation motion in superalloys during high-temperature lowstress creep", Acta mater, 53 (2005), 4623-4633.

32. T.M. Pollock and A.S. Argon, "Creep resistance of CMSX-3 nickel base superalloy single crystals", Acta Metall. Mater, 40 (1) (1992), 1-30.

33. K. Serin et al. "A kinetic study of $\gamma$-channel widening during high temperature and low stress creep of superalloy single crystals", (Paper presented at EUROMAT 2000, Tours, France, 2000), 1303-1308.

34. A. Dlouhy, M. Probst-Hein, and G. Eggeler, "Static dislocation interactions in thin channels between cuboïdal particles", Material Science and Engineering, A309-310 (2001), 278-282.

35. G. Eggeler and A. Dlouhy, "On the transformation of $<010\rangle$-dislocations in the $\gamma$-phase of superalloy single crystals during high temperature low stress creep", Acta mater, 45 (10) (1997), 4251-4262.

36. R. Srinivasan, G.F. Eggeler, and M.J. Mills, " $\gamma$ '-cutting as a rate-controlling recovery process during high temperature and low-stress creep of superalloy single crystals", Acta mater, 48 (2000), 4867-4878.

37. J. Cormier et al., "Non-isothermal creep behavior modeling of Ni-based single crystal superalloys under very high temperature/low stress conditions", To be published. 